\title{
Concepts and Constituents to Design Communicative Activities
}

\author{
Dr. K. Yugandhar \\ Associate Professor, Department of English, Dilla University, Dilla, Ethiopia, Africa
}

\begin{abstract}
The fundamental aspect of communicative language teaching approach in an English Language class is communicative competence. Communicative activities facilitate ample opportunities to experiment with the use of appropriate language and take decisions in using the language according to his/her communicative needs. These activities focus on the three overlapping and recursive elements in acquiring language are cognitive presence, social presence and teaching presence. To develop this kind of learning environment designing suitable activities is crucial. This paper focuses a few important concepts in designing and implementing communicative activities in an English class.

Communicative activities involve in achieving an outcome that is appreciated by the class with the major constituents - goals, input and activities. To execute the communicative activities effectively, the students are provided with suitable materials and positive ambiance with supportive guidance. Exposing students to a relevant, engaging learners to experience the language and providing opportunities to use language are very important concepts of language acquisition that are to be scrupulously considered while designing communicative activities. Communicative activities offers a change from the traditional teaching routines by facilitating the students all three recursive elements - cognitive presence, social presence and teaching presence to acquire and develop their language skills.
\end{abstract}

Keywords: Communicative Language Teaching, Designing and Implementing Communicative Activities, Conducive Ambiance for Language Acquisition.

\section{INTRODUCTION}

The fundamental aspect of communicative language teaching approach in an English class is the communicative competence. Communicative activities create conducive ambiance to use, experiment and learn language with the support of teacher and the peers. The activities facilitate ample opportunities to experiment with the use of appropriate language and take decisions in using the language according to his/her communicative needs. These activities focus on functional as well as structural aspects of language with a special emphasis on the real life use of language in day to day life situations.

For meaningful and effective activities, learners need to be engaged in private reflection and critical discourse, blending the subjective thoughts with the shared worlds of learning within a community of inquiry. According to Garrison and Anderson, the three overlapping and recursive elements in acquiring language are cognitive presence, social presence and teaching presence. Cognitive presence is the knowledge building through the cyclical pattern of "trigger, exploration, integration and resolution." Social presence is the ability of students to build interpersonal relationships through open and cohesive communication. Teaching presence is the adhesive that holds the other two elements together by facilitating and directing the communication to achieve learning outcomes and educational goals. These three elements of cognitive, social and teaching presence provide a coherent framework for the analysis of communicative activities in an English class. In such a climate, students learn by "negotiating meanings, diagnosing misconceptions and challenging accepted beliefs" (Garrison \& Anderson, 2003, p. 28). This kind of learning environment could be very easily created with well-designed language activities.

\section{Designing Communicative ACtivities}

To support the design of an activity for learning, any existing learning objectives must be described not only in terms of information within it, but also in term of activities that it can support or in terms of learning objects that can result from these activities. Jane Wills describes task or activity as a goaloriented work with a clear purpose. 


\section{Dr. K. Yugandhar}

Learners' characteristics must be considered only after an activity is defined, in term of their learning support needs rather than in term of their ability to understand content. Carefully designed sub-tasks within an activity are to take learners from one level of learning to another, from simple to complex, from lower to higher order thinking, from observation and experimentation to generalizations, application and innovation, from problem understanding to articulation of best solution. The activities can be designed and used in these four stages:

$>$ Construct - to prepare a psychological model of an activity that suits to the learning objective. Teacher needs to identify suitable topic, define learning objective, construct learning activity, identify learning objective, and find the necessary material to support the learning process for good construction of an activity.

$>$ Produce - to obtain suitable method and material according to the psychological model of the activity. Teacher is expected to develop resources for achieving the objective by integrating suitable method and material in the activity.

$>$ Implement - to execute the activity in the class providing suitable environment for learning. It would be better to facilitate learning experience by providing encouraging ambiance for improving language skills with self-learning techniques in the activity.

$>$ Evaluate - to find the value of the activity in the process of acquiring the language skills. Such activities can be improved further by finding the involvement, learning, and achievement of the learning objective to use it as feedback of the activity or construct of the next activity.

Communicative activities involve in achieving an outcome, creating a final product that can be appreciated by the class. An activity is a three stage process for effective language learning which includes - 1. Pre-task - introduction to the topic and task 2. Task cycle - task planning and report and 3. Subject focus - analysis and practice.

\section{Constituents of Communicative Activities}

Communicative activities refers to tasks to use the language, not exercises to practice individual language elements. Tasks contain some form of input data which might be verbal or non-verbal. An activity is in some way derived from the input and sets out what the learners are to do in relation to the input. Nunan (1989) suggests that the communicative tasks will contain a goal, input, activities, settings and roles. Goals of tasks are to develop students' communicative competence including socio-linguistic competence, discourse competence and strategic competence. Goals, input and activities are the three major constituents of communicative tasks.

\subsection{Goals}

Goals mean the general intentions behind any given communicative tasks and learning tasks. They may be related to a range of general outcomes (communicative, effective or cognitive) or may directly describe teacher or learner behaviour. The making of goals is very important before learners' communicative activities. Clark (1987) divided communicative goal into three goal areas: i. Establishing and maintaining interpersonal relationships, and through this to exchange information, ideas, opinions, attitudes and feelings, and to get things done. ii. Acquiring information from more or less 'public' sources in the target language (e.g. books, magazines, newspapers, brochures, notices, films, television, slides, tape, radio, public announcements, lectures, reports etc.) and using this information in some way. iii. Listening to, reading, enjoying and responding to creative and imaginative uses of the target language (e.g. stories, poems, songs, rhymes, drama) and, for certain learners, creating them themselves. Goals are generally referenced against the sorts of things which learners want to do with the language outside the classroom. Typical goal statements include:

$>$ to develop the skills necessary to take part in academic study

$>$ to obtain sufficient oral and written skills

$>$ to communicate socially in the target language

$>$ to improve survival skills necessary to obtain goods and services

After realizing goals, learners need to have enough materials as input before participating in communicative activities. Input is another important element of communicative tasks, it is necessary to analyze input as is indispensable to a communicative task. 


\subsection{Input}

The theories of second language acquisition agree that, for learning a modern language, learners must be exposed to a considerable amount of language input either in natural or artificial teaching settings. Rod Ellis considered that input is used to refer to the language that is addressed to the foreign language learner either by a native speaker or by another foreign language learner. The suggestion being made by Krashen, then, is that students can acquire language on their own provided that they get a great deal of comprehensible input.

A further distinction needs to be made, however, between two different types of input: roughly-tuned input and finely-tuned input. The former is language at a level slightly above the students' abilities. The latter is language selected very precisely to be at exactly the students' level. For our purposes finely-tuned input can be taken to mean that language which we select for conscious learning and teaching. In communicative classroom, the approaches of input often refer to listening to extract specific information and reading to extract specific information. Listening to Extract Specific Information and Reading to Extract Specific Information are two main approaches of input that are useful and practical.

\subsection{Activities}

Activities refer to the behaviour that participants do with the input, which forms the point of departure for the learning task. Nunan proposes three general ways of characterizing activities: 1) rehearsal for the real world (authenticity); 2) practice of skills; and 3) fluency / accuracy. According to Penny's view, an effective communicative activity includes four aspects as the following:

$>$ Learners talk a lot: As much as possible of the period of time allotted to the activity is in fact occupied by learner talk. This may seem obvious, but often most time taken up with teacher talk or pauses.

> Participation is even: Classroom discussion is not dominated by a minority of talkative participants: all get a chance to speak, and contributions one fairly evenly distributed.

$>$ Motivation is high: Learners are eager to speak: because they are interested in the topic and have something new to say about it, or because they want to contribute to achieving a task objective.

$>$ Language is of an acceptable level: Learners express themselves in utterances that are relevant, easily comprehensible to each other, and of an acceptable level of language accuracy.

\section{Concepts of Language Acquisition to Design Communicative Activities}

The students are provided with suitable material and are allowed to involve them to process the information in a positive ambiance before they use during the communicative activities.

\subsection{Expose Students to a Relevant, Effective and Comprehensible Language}

In order to acquire the ability to use the language effectively the learners need a lot of experience of the language being used in a variety of different ways for a variety of purposes. If the learners do not think and feel whilst experiencing the language, they are unlikely to achieve language acquisition and development. They need to be able to understand enough of this input to gain positive access to it and it needs to be meaningful to them. (Krashen, 1999; Tomlinson, 2010)

\subsection{Engage Learners both Emotionally and Cognitively to Experience the Language}

Students process the given material to transfer high level skills such as predicting, connecting, interpreting and evaluating. This is true of learners' responses to the content of what they are reading, writing, listening to or saying but the emotions stimulated by the self-access learning experience need to be positive and pleasurable to maximize the learning. Such noticing is most salient when a learner has been engaged in a text and then returns to it to make discoveries about its language use. This is likely to lead to the learner paying attention to similar uses in subsequent inputs and to increase the potential for eventual acquisition. (Schmidt \& Frota, 1986; Tomlinson, 2007)

\subsection{Provide Opportunities to Use Language in Communicative Activities}

Communicating in the target language allows learners to gain feedback on the hypotheses they have developed and on their ability to make use of their hypotheses effectively. If they are interacting, they 


\section{Dr. K. Yugandhar}

are also being pushed to clarify and elaborate and they are also likely to elicit meaningful and comprehensible input from their peers. (Swain, 2005)

It is believed that the goal of English language learning is construction of advanced knowledge representations in the form of mental models. The goal of activity-based learning is for learners to construct mental models that allow for 'higher-order' performance such as applied problem solving and transfer of information and skills. Suitable input and positive classroom environment encourage students to participate in communicative activities.

\section{Practicalities in Designing Communicative ACtivities}

Task design is the most important element in Task based Language Teaching. Teacher needs to have a clear idea about kinds of tasks, whether focus on language form or not and how difficult the tasks should be in order to facilitate learning of different learners with different learning levels. Four basic principles relating to communicative tasks design are discussed that help teachers to design the tasks for improving language skills for college students.

\subsection{Meaningful Tasks}

Halliday (1975) emphasizes that learning a foreign language involves the acquisition of a new system for realizing familiar meanings. Language develops in response to the need to mean and to understand what others mean. It follows that materials we offer learners should allow them to focus first on meanings in contexts and then go on to look at the wordings that realize the meanings.

From these viewpoints, we can argue that any pedagogical process which supports natural acquisition processes should therefore lead from meanings to wordings. This is a major principle behind a taskbased approach to course design. In setting learners a task to achieve (e.g., a problem to solve), the emphasis is first on learners' exchanging meanings to complete the task, using whatever language they can recall. Then they examine the language that fluent speakers or writers used to do the same task and focus on typical words, phrases and patterns (i.e., wordings) that occurred (Willis, 1998a).

\subsection{Focus on Language Form}

Of the many issues in our field, that of focusing on form or focusing on meaning has probably been one of the most widely discussed. Most applied linguists argue that both are important, and that they are in fact two sides of a single coin and not the opposing issues.

Meanwhile, when we design a task or an activity, we mean that a good guidance to each task, even a subtask is usually shown in the language teaching or learning, so as to have learners understand and use language effectively in the communicative activity, through a rich array of task practice. Although many students acquire a new language with little focus on language form, there is now some evidence that learners do better if, at some point, their attention is drawn to typical features of language form (Skehan, 1994a). This can be done in two ways:

$>$ Through consciousness-raising exercises highlighting frequently used language items, to help learners perceive patterns (Schmidt, 1990), and systematize what they know.

$>$ By challenging learners to communicate in circumstances where accuracy matters, so they feel the need, at a prior planning stage, to organize their ideas clearly and to check that their lexical choices, their grammar and pronunciation are accurate.

\subsection{Authenticity}

If learners never get to listen to or read authentic texts in the supportive atmosphere of the classroom the challenge of functioning effectively in genuine communication outside the classroom will be that much greater (Nunan, 1999).

Non-authentic data can provide learners with examples of target grammar and vocabulary in texts that are simple enough to enable learners to understand and process the language. As such, they are valuable resources for learners, particularly in the early stages of learning. So, when we design a task, we have to deal with the relationship between its authenticity and the contents in the texts and try to have learners understand and practise a language in a naturally authentic language situation. In many ways authenticity of tasks can be achieved and pedagogic tasks can have more meanings and be more related to the real world. These include making tasks more authentic though the following means: 
a. Through genuine task purposes: Willis (1998) asserts that one of the crucial aspects of task authenticity is whether real communication takes place. So the first way to make tasks authentic is to find out a genuine purpose for the language to be learned, only when there is a purpose will real meaningful communication take place.

b. Through real world targets: Working within a needs-analysis framework, Long and Crookes (1992) argue that pedagogic tasks must be related to real-world target tasks. Examples given by them are: buying a train ticket, renting an apartment, reporting a chemistry experiment taking lecture notes etc.

c. Through classroom interactions: A classroom is a special society. Students and teachers get together for a common purpose. So, pedagogic tasks can be authentic through classroom interactions. Teachers should have the ability to explore the potential authenticity of the learning situation in classrooms.

d. Through learners' engagement: Another crucial element of task is whether it is relevant to the learners. So in order to make tasks more authentic, task designers must take learners' engagement into consideration. It's true that some tasks are authentic to some learners but not at all to others.

\subsection{Reasonable Task Difficulty}

Researchers have proved that task difficulty have great influences on the effect of tasks, namely the accuracy, complexity and fluency of the learners' language outcomes. So, proper choice of difficulty in different stage of a TBLT class is of great importance.

In order to control the difficulty of tasks, teachers should know how to make tasks easy and difficult to meet different needs. Nunan reviews some factors relating to task difficulty. He and Candlin offer two lists in 1987, one of which focuses solely on the nature of the task, while the other is based upon the cognitive operations required of the learners. The first list which is offered by Candlin is as follows:

$>$ cognitive complexity

$>$ communicative difficulty

$>$ whether the task follows a general sequence of operations or whether this is unclear

$>$ linguistic complexity

$>$ continuity between tasks

The following is the second list which was issued by Nunan and Candlin:

$>$ attending to or noticing or recognizing the input

$>$ making sense of the input

$>$ processing information

$>$ transferring and generalizing what is learned

After outlining four basic principles relating to communicative tasks design, the paper focuses on the description and illustration of practical process of course and materials design which takes these principles into account.

\section{Conclusion}

Use of communicative activities in an English class is a truthful approach requiring a shift in methodological focus on traditional materials. The major challenge for a teacher is whether a set of materials adaptation or redesigning of the material is suitable for the particular group of students. Once the teacher sets the suitable ambiance, students enjoy the acquisition of language skills with a spirit of cooperation and enthusiasm. Communicative activities has been proved to be effective in teaching English in promoting the learners' competence in using the language. Communicative activities offers a change from the traditional teaching routines by facilitating the students all three recursive elements - cognitive presence, social presence and teaching presence to acquire and develop their language skills. 


\section{REFERENCES}

Brown, Robert Winston, (2003) Learning, Hierarchical Storage, Assembly and Recall. Proceedings of the 2003 ASEE/WFEO International Colloquium

Brumfit, C. and Johnson, K. (1979) (ed.) The Communicative Approach to Language Teaching. New York: Oxford University Press.

Garrison, D. R., \& Anderson, T. (2003). E-learning in the 21st century: A framework for research and practice. London: Routledge Farmer.

Krashen, D.S. Second Language Acquisition and Second Language Learning. New York: Prentice Hall International 1988.

Laurillard, D. (2002). Rethinking education for the knowledge society. Educase,37 (1), 16- 25.

Nunan, D. (2004). Task-based language teaching. Cambridge, UK: Cambridge University Press.

Nunan, D. (2006). Task-based language teaching in the Asia context: Defining 'task'. Asian EFL journal, 8(3), Article 1. Retrieved from http://www.asian-efl-journal.com/Sept_06_dn.php

Robinson, P. (2007). Task complexity, theory of mind, and intentional reasoning: Effects on L2 speech production, interaction, uptake and perceptions of task difficulty. International Review of Applied Linguistics in Language Teaching, 45(3).

\section{AUTHOR's BIOGRAPHY}

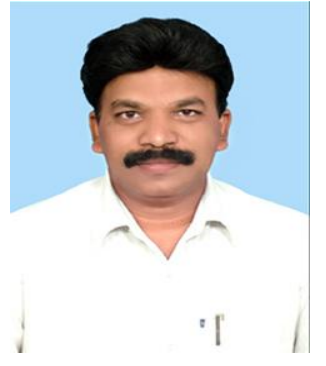

Dr.K.Yugandhar, Associate Professor of English, has received Ph.D. in English from Jawaharlal Nehru Technological University, Hyderabad, India. He has been teaching English language and literature to graduate and post graduate students for eighteen years. Most of his research work focuses on interlacing technology with pedagogical concepts to improve the quality of Education in general and English Language Teaching in particular. He received credentials in ELT from Osmania University, Andhra University, Kakatiya University and Central Institute of English and Foreign Language, Andhra Pradesh, India. 